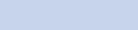

\title{
DNA methylation profiling in MEN1-related pancreatic neuroendocrine tumors reveals a potential epigenetic target for treatment
}

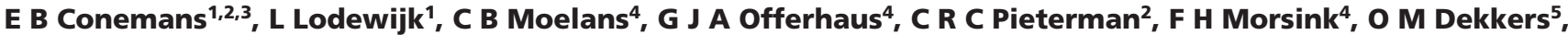
W W de Herder ${ }^{6}$, A R Hermus , A N van der Horst-Schrivers ${ }^{8}$, M L Drent ${ }^{3}$, P H Bisschop ${ }^{9}$, B Havekes ${ }^{10}$, L A A Brosens ${ }^{4}$, K M A Dreijerink ${ }^{2,3}$, I H M Borel Rinkes ${ }^{1}$, H Th M Timmers ${ }^{11,12}$, G D Valk ${ }^{2}$ and M R Vriens ${ }^{1}$

Departments of ${ }^{1}$ Surgery, ${ }^{2}$ Internal Medicine, University Medical Center Utrecht, Utrecht, The Netherlands, ${ }^{3}$ Section Endocrinology, Department of Internal Medicine, VU University Medical Center, Amsterdam, The Netherlands, ${ }^{4}$ Department of Pathology, University Medical Center Utrecht, Utrecht, The Netherlands, ${ }^{5}$ Departments of Endocrinology and Metabolism and Clinical Epidemiology, Leiden University Medical Center, Leiden, The Netherlands, ${ }^{6}$ Department of Internal Medicine, Erasmus Medical Center, Rotterdam, The Netherlands, ${ }^{7}$ Department of Endocrinology, Radboud University Medical Center, Nijmegen, The Netherlands, ${ }^{8}$ Department of Endocrinology, University Medical Center Groningen, Groningen, The Netherlands, ${ }^{9}$ Department of Endocrinology and Metabolism, Academic Medical Center, Amsterdam, The Netherlands, ${ }^{10}$ Division of Endocrinology, Department of Internal Medicine, Maastricht University Medical Center, Maastricht, The Netherlands, ${ }^{11}$ Regenerative Medicine Center and Center for Molecular Medicine, University Medical Center Utrecht, Utrecht, The Netherlands, and ${ }^{12}$ German Cancer Consortium (DKTK) Partner Site Freiburg, German Cancer Research Center (DKFZ) and Department of Urology, Medical Center-University of Freiburg, Freiburg, Germany

Correspondence should be addressed to M R Vriens

Email

mvriens@umcutrecht.nl

\begin{abstract}
Objective: Epigenetic changes contribute to pancreatic neuroendocrine tumor (PanNET) development. Hypermethylation of promoter DNA as a cause of tumor suppressor gene silencing is a well-established oncogenic mechanism that is potentially reversible and therefore an interesting therapeutic target. Multiple endocrine neoplasia type 1 (MEN1) is the most frequent cause of inherited PanNETs. The aim of this study was to determine promoter methylation profiles in MEN1-related PanNETs.

Design and methods: Methylation-specific multiplex ligation-dependent probe amplification was used to assess promoter methylation of 56 tumor suppressor genes in MEN1-related $(n=61)$ and sporadic $(n=34)$ PanNETs.

Differences in cumulative methylation index (CMI), individual methylation percentages and frequency of promoter hypermethylation between subgroups were analyzed.

Results: We found promoter methylation of a large number of potential tumor suppressor genes. CMI (median CMI: 912 vs $876, P=0.207$ ) was the same in MEN1-related and sporadic PanNETs. We found higher methylation percentages of CASP8 in MEN1-related PanNETs (median: $59 \%$ vs $16.5 \%, P=0.002$ ). In MEN1-related non-functioning PanNETs, the CMI was higher in larger PanNETs $(>2 \mathrm{~cm}$ ) (median: 969.5 vs $838.5 ; P=0.021$ ) and in PanNETs with liver metastases (median: 1036 vs 869; $P=0.013$ ). Hypermethylation of MGMT2 was more frequent in non-functioning PanNETs compared to insulinomas (median: $44.7 \%$ vs $8.3 \% ; P=0.022$ ). Hypermethylation of the Von Hippel-Lindau gene promoter was observed in one MEN1-related PanNET and was associated with loss of protein expression. Conclusion: Promoter hypermethylation is a frequent event in MEN1-related and sporadic PanNETs. Targeting DNA methylation could be of therapeutic value in MEN1 patients with advanced PanNETs.

(C) 2018 European Society of Endocrinology Printed in Great Britain
Published by Bioscientifica Ltd. 


\section{Introduction}

Hypermethylation of $\mathrm{CpG}$ sites in promoter regions of tumor suppressor genes, leading to gene silencing, is a well-characterized epigenetic process in the development of a variety of cancers (1).

Because DNA methylation is potentially reversible, it may serve as an interesting therapeutic target (2). In fact, the DNA methyl transferase inhibitors decitabine and azacitidine are approved to treat hematological cancers (3). Promoter hypermethylation of selected genes has been reported in sporadic pancreatic neuroendocrine tumors (PanNETs) (4). Although the estimated incidence of PanNETs in several population-based studies is $<1 \%$ (5), the incidence has increased considerably over the last decades (6). The usual tumor suppressor and oncogenes involved in development of other solid tumors are infrequently mutated or deleted in PanNETs (7). In contrast, whole exome sequencing has revealed that genes encoding proteins involved in chromatin remodeling and modification are commonly mutated in sporadic PanNETs (8). Somatic inactivating mutations of the MEN1 gene, encoding the tumor suppressor menin, were seen in $37-44 \%$ of sporadic PanNETs $(8,9)$. One of the best-characterized functions of menin is to activate gene transcription through chromatin modification. In addition to genetic changes caused by mutations of the MEN1 gene, other epigenetic mechanisms such as DNA methylation may to contribute to PanNET tumorigenesis in MEN1 (4). MEN1 is the most frequent cause of inherited PanNETs and is caused by germ-line mutations in MEN1 (10). In accordance with Knudson's second hit hypothesis, loss of heterozygosity (LOH) of the MEN1 gene is an early event in PanNET development in MEN1 patients $(11,12,13)$. PanNETs are an important cause of death in MEN1, but little is known about prognostic factors and the best therapeutic strategies (14). Unraveling the biological processes and oncogenic pathways involved in tumorigenesis in MEN1 patients is an important step toward the development of prognostic markers as well as therapeutic targets. Therefore, the aim of this study was to determine promoter methylation profiles in MEN1-related PanNETs.

\section{Subjects and methods}

\section{Patients and clinical definitions}

Both MEN1-related and sporadic well-differentiated PanNETs were included in this study. Selection of
PanNET tissue from MEN1 patients has been described extensively before (15). In summary, the longitudinal DutchMEN1 Study Group (DMSG) database, which covers $>90 \%$ of the Dutch MEN1 population aged 16 years and older, was used. Patients, who had undergone surgery for PanNETs between 1985 and the end of 2013, were included. Formalin-fixed paraffin-embedded tissue blocks from the largest PanNET per patient were collected in collaboration with 'the nationwide network and registry of histo- and cytopathology in the Netherlands' (PALGA) (16). Clinical data were collected until December 2013.

Sporadic PanNETs were selected from the database of the UMC Utrecht tissue bank. Patients with a recorded history suggestive of a hereditary endocrine tumor syndrome were excluded. The Medical Ethics Committee of the UMC Utrecht concluded that the Medical Research Involving Human Subjects Act (WMO) was not applicable to this retrospective study. The study was performed according to national guidelines with respect to the use of excess tissue for scientific research. Patients with objections against this use were not included. Ethical approval for the research protocol was obtained from the Medical Ethics Committee of the UMC Utrecht.

WHO grade was based on both the Ki67 labeling index (LI) and the mitotic count $(17,18)$. Tumor size as mentioned in the pathology reports was used and dichotomized at $2 \mathrm{~cm}$. Definition of insulinoma and PanNET-related liver metastases in MEN1 patients has been described extensively before (14). Data on the liver metastases were not available for sporadic cases. We included 61 MEN1 PanNETs and 34 sporadic PanNETs. Baseline characteristics are shown in Tables 1 and 2 . Median age of MEN1 patients was lower compared to sporadic patients ( 41 vs 57.5 years, $P \leq 0.001$ ) and PanNETs from sporadic patients were more frequently WHO G2 tumors $(35.3 \%$ vs $16.4 \%, P=0.045)$.

\section{DNA extraction}

Tumor areas with at least 30\% tumor cells were identified on H\&E slides. Corresponding areas were micro-dissected from deparaffinized $5 \mu \mathrm{m}$ slides and suspended in direct lysis buffer (10 mM Tris-HCl pH 8.0/0.1 mM EDTA). After overnight incubation with proteinase $\mathrm{K}(10 \mathrm{mg} / \mathrm{mL}$; Sigma Aldrich) at $56^{\circ} \mathrm{C}$, followed by boiling for $10 \mathrm{~min}$, samples were centrifuged and DNA was extracted. DNA concentrations were measured with a spectrophotometer (NanoDrop ND-1000, Thermo Scientific). 
Table 1 Clinical and pathological characteristics: patients with MEN1-related or sporadic PanNETs.

\begin{tabular}{|c|c|c|c|}
\hline & MEN1 $(n=61)$ & Sporadic $(n=28)$ & $P$ value \\
\hline \multicolumn{4}{|l|}{ Gender, $n(\%)$} \\
\hline Male & $29(47.5)$ & $18(52.9)$ & 0.672 \\
\hline Female & $32(52.5)$ & $16(47.1)$ & \\
\hline $\begin{array}{l}\text { Age at PanNET } \\
\text { resection in years* }\end{array}$ & $41(20-60)$ & $57.5(27-81)$ & 0.000 \\
\hline \multicolumn{4}{|l|}{ PanNET size, $n(\%)$} \\
\hline$\leq 2 \mathrm{~cm}$ & $25(41)$ & $21(61.8)$ & 0.130 \\
\hline$>2 \mathrm{~cm}$ & $33(54.1)$ & $13(38.2)$ & \\
\hline Unknown & $3(4.9)$ & 0 & \\
\hline \multicolumn{4}{|l|}{ WHO grade, $n(\%)$} \\
\hline G1 & $51(83.6)$ & $22(64.7)$ & 0.045 \\
\hline G2 & $10(16.4)$ & $12(35.3)$ & \\
\hline \multicolumn{4}{|l|}{ Type, $n(\%)$} \\
\hline Insulinoma & $13(21.3)$ & $11(32.4)$ & 0.326 \\
\hline Other & $47(77)$ & $23(67.6)$ & \\
\hline Unknown & $1(1.6)$ & 0 & \\
\hline
\end{tabular}

NA, not applicable; PanNET, pancreatic neuroendocrine tumor. *Values presented as median (range)

\section{Methylation-specific multiplex ligation-dependent probe amplification}

The principle of methylation-specific multiplex ligationdependent probe amplification (MS-MLPA) has been described before (19). SALSA MS-MLPA tumor suppressor probe mixes ME001-C2, ME002-C1 and ME004-A1 were used in this study, and MS-MLPA was performed according to the manufacturer's protocol (MRC Holland). The three tumor suppressor gene probe mixes contained 27, 26 and 31 Hhal-sensitive probes respectively and 14, 15 and 9 reference probes (without the Hhal restriction site). In this study, 56 different tumor suppressor genes were included. Supplementary Table 1 (see section on supplementary data given at the end of this article) shows an overview of essential information regarding the genes included in the three probe mixes (Supplementary Table 1).

For each MS-MLPA reaction, at least 50 ng DNA was used. All runs were performed in a Veriti 96 Well Thermo Cycler (Applied Biosystems). A water sample, a positive control (A549 cells or MCF-7 cells treated with M.SssI DNA methyltransferase) and negative controls (derived from human blood) were included in every MLPA run. PCR fragments were separated by capillary electrophoresis (ABI 3730 capillary sequencer, Applied Biosystems). Genemapper software version 4.1 (Applied Biosystems) and Coffalyser.NET analysis software (MRC Holland) were used to calculate methylation status.
Table 2 Clinical and pathological characteristics: patients with MEN1-related NF-PanNET or insulinoma.

\begin{tabular}{|c|c|c|c|}
\hline & $\begin{array}{c}\text { NF-PanNET } \\
(n=47)\end{array}$ & Insulinoma $(n=13)$ & $P$ value \\
\hline \multicolumn{4}{|l|}{ Gender, $n(\%)$} \\
\hline Male & $26(55.3)$ & $2(15.4)$ & 0.013 \\
\hline Female & $21(44.7)$ & $11(84.6)$ & \\
\hline $\begin{array}{l}\text { Age at PanNET } \\
\text { resection in } \\
\text { years* }\end{array}$ & $42(20-60)$ & $31(20-46)$ & 0.002 \\
\hline \multicolumn{4}{|l|}{ PanNET size, $n(\%)$} \\
\hline$\leq 2 \mathrm{~cm}$ & $18(38.3)$ & $6(46.2)$ & 0.759 \\
\hline$>2 \mathrm{~cm}$ & $26(55.3)$ & $7(53.8)$ & \\
\hline Unknown & $3(6.4)$ & 0 & \\
\hline \multicolumn{4}{|l|}{ WHO grade, $n(\%)$} \\
\hline G1 & $39(83)$ & $11(84.6)$ & 1 \\
\hline $\mathrm{G} 2$ & $8(17)$ & $2(15.4)$ & \\
\hline \multicolumn{4}{|l|}{$\begin{array}{l}\text { Liver metastases, } \\
\quad n(\%)\end{array}$} \\
\hline Yes & $8(17)$ & $1(7.7)$ & 0.668 \\
\hline No & $38(80.9)$ & $12(92.3)$ & \\
\hline Unknown & $1(2.1)$ & 0 & \\
\hline Follow up in years* & $5.75(0-28.5)$ & $5.75(1.25-17.75)$ & 0.475 \\
\hline
\end{tabular}

NA, not applicable; NF-PanNET, non-functioning PanNET; PanNET, pancreatic neuroendocrine tumor.

*Values are presented as median (range)

\section{Immunohistochemistry}

Immunohistochemistry for menin in sporadic PanNETs was performed on tissue micro-array slides including a subset of the sporadic cohort using a polyclonal antibody for menin (Bethyl Laboratories, A300-105A, 1:1600, ARS pH 5.8 pre-treatment and incubation at room temperature for $1 \mathrm{~h}$ ). Menin staining was considered either positive ( $>30 \%$ positive nuclei) or negative $(\leq 30 \%$ positive nuclei) (15).

For detection of pVHL, a monoclonal antibody was used (BD, clone Ig32, Cat.no. 556347, 1:200, ARS pH6 pre-treatment and overnight incubation at $4^{\circ} \mathrm{C}$ ).

Briefly, $4 \mu \mathrm{m}$ sections were deparaffinized and blocked for endogenous peroxidase activity by immersion in $0.3 \% \mathrm{H}_{2} \mathrm{O}_{2}$ in methanol. Antigen retrieval (indicated as ARS) was performed in sodium citrate buffer $(0.01 \mathrm{M} /$ $\mathrm{pH}$ 6.0) for $20 \mathrm{~min}$ at $100^{\circ} \mathrm{C}$. Nonspecific binding sites were blocked using Protein Block Serum free (DAKO), followed by primary antibody incubation. Antibody binding was visualized using the BrightVision + polyHRP detection system (ImmunoLogic, Diemen, The Netherlands), with 3,3-diamino-benzidine as chromogen (DAB, Sigma). Sections were counterstained with hematoxylin, dehydrated and coverslipped using Pertex. 


\section{Statistics}

The cumulative methylation index (CMI) was calculated as the sum of the methylation percentage of all genes as described before (20). The Mann-Whitney $U$ test was performed to compare CMI and methylation of individual genes between MEN1-related and sporadic PanNETs. Furthermore, sporadic PanNETs were subdivided into menin staining-positive and menin staining-negative tumors. The Kruskal-Wallis test was used to compare MEN1-related PanNETs with menin-positive and -negative sporadic PanNETs. Within the MEN1-related PanNETs, subgroups analysis for differences in CMI and methylation of individual genes was performed. Spearman correlation coefficient was calculated for the association between methylation data and age when appropriate. In a different (dichotomous) approach, 15\% methylation was defined as the cut-off value for promoter hypermethylation. This value was previously determined based on titration experiments in cell lines and has been used before in similar studies $(21,22,23)$. The Fisher exact test was applied to compare frequency of hypermethylation for individual genes of one subgroup with another. Twosided $P$ values $<0.05$ were considered to be statistically significant. All statistical analyses were performed using IBM SPSS Statistics 23.0.

\section{Results}

The CMI was calculated and differences in methylation percentages patterns for individual genes between subgroups were analyzed (continuous data analysis). This showed no significant differences in the CMI of MEN1related and sporadic PanNETs (median CMI: 912 vs 876; $P=0.207)$. In MEN1 subgroup analysis of non-functioning PanNETs, CMI was higher in larger PanNETs $(>2 \mathrm{~cm})$ (median: 969.5 vs 838.5; $P=0.021$ ) and higher in PanNETs with liver metastases (median 1036 vs $869 ; P=0.013$ ).

When comparing methylation percentages at individual gene loci, higher percentages of CASP8 methylation were found in MEN1-related tumors compared to sporadic PanNETs (median: 59\% vs $16.5 \%$; $P=0.002$ ). The methylation percentage of CASP8 in menin-negative sporadic PanNETs was comparable to MEN1-related PanNETs, but lower in menin-positive sporadic PanNETs (respectively median $59 \%$ vs $44 \%$ vs $19 \% ; P=0.046$ ) (Fig. 1 ). MEN1-related insulinomas showed a higher methylation percentage than nonfunctioning PanNETs for RASSF1_1 (median: 70\% vs 47\%; $P=0.001)$. There was no correlation between RASSF1_1
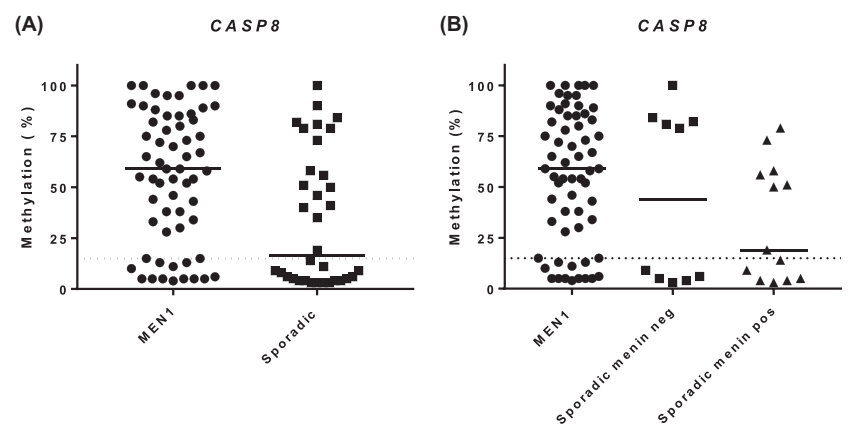

Figure 1

Promoter methylation of CASP8. (A) In MEN1-related ( $n=61)$ and sporadic PanNETs $(n=34, P=0.002)$. (B) In MEN1-related $(n=61)$ and sporadic PanNETs after subdividing sporadic PanNETs into menin-negative $(n=10)$ and menin-positive tumors $(n=13),(P=0.046)$. Dotted line represents cut-off value for hypermethylation (15\%).

methylation percentage and age (Spearman correlation coefficient $-0.097 ; P=0.348$ ). Other relevant differences in quantitative methylation of individual genes between MEN1 subgroups were not observed. In the dichotomous analysis, we found that both in MEN1-related and sporadic PanNETs, a large number of potential tumor suppressor showed promoter hypermethylation (Fig. 2). In general, the frequency of hypermethylation of individual genes was comparable between these two groups, except for CASP8 (77\% vs 50\%; $P=0.011), R A S S F 1 \_1$ (98.4\% vs 79.4\%,

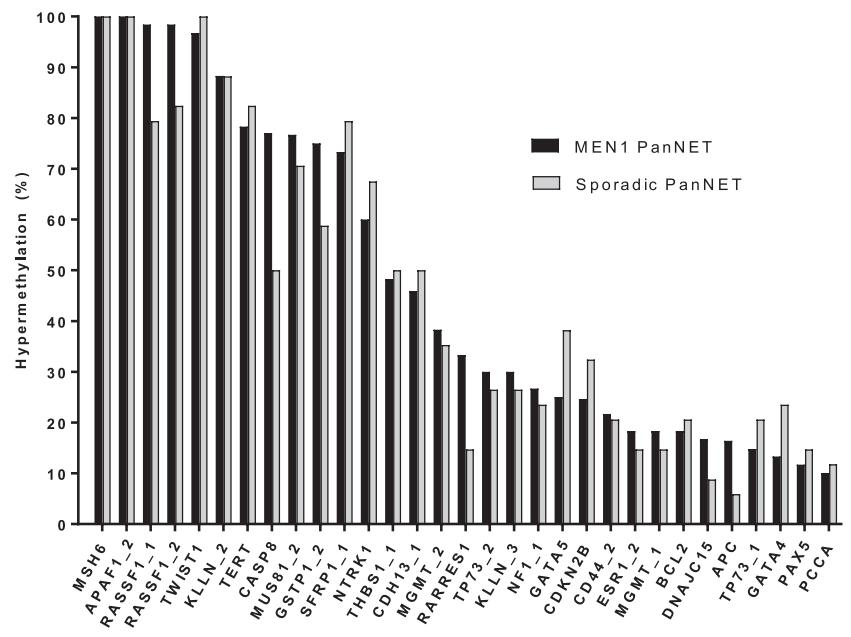

Figure 2

Promoter hypermethylation of genes in both MEN1-related and sporadic PanNETs. Cut-off value for promoter hypermethylation was $15 \%$. Only gene loci with hypermethylation in $>10 \%$ of the MEN1-related tumors are shown. 
$P=0.003)$ and RASSF1_2 (98.4\% vs $82.4 \% ; P=0.008)$. In these cases, hypermethylation was more frequent in MEN1-related PanNETs. Promoter hypermethylation of MEN1 (2 different probes included) was not seen in MEN1-related or in sporadic PanNETs. Analysis of MEN1 subgroups revealed that hypermethylation of MGMT_2 is more frequently seen in non-functioning PanNETs compared to insulinomas $(44.7 \%$ vs $8.3 \% ; P=0.022)$ (Fig. 3). There was no correlation between MGMT_2 methylation percentage and age (Spearman correlation coefficient $0.187 ; P=0.071$ ).

Interestingly, in one grade 2 MEN1-related PanNET, the methylation percentage of $V H L$ was remarkably high (VHL_2 73\% and VHL_1 36\%). Hypermethylation of $V H L$ was not seen in any other MEN1 PanNET. Immunohistochemistry showed loss of VHL expression in this specific tumor, whereas expression was normal in another PanNET of the same patient that showed no VHL promoter hypermethylation (Fig. 4).

\section{Discussion}

We present the first promoter hypermethylation analysis of tumor suppressor genes in MEN1-related PanNETs. In this study, we included a comprehensive series of

\section{G M T 2}

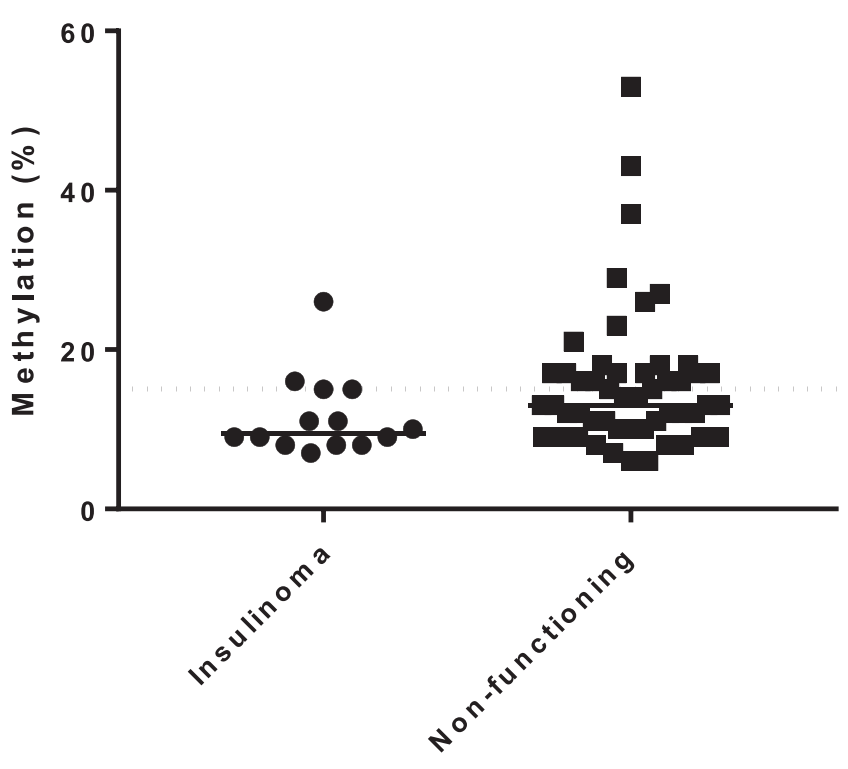

Figure 3

Promoter methylation of MGMT in MEN1-related insulinomas and non-functioning PanNETs. Dotted line represents the $15 \%$ cut-off value for hypermethylation $(P=0.022)$.

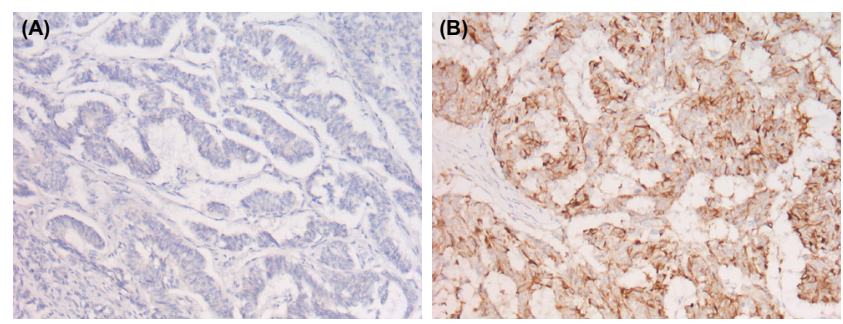

Figure 4

Promoter hypermethylation and protein expression of VHL differs between different PanNETs of the same MEN1 patient.

(A) VHL protein expression is lost in the PanNET with promoter hypermethylation of VHL. (B) In another PanNET of the same patient without promoter hypermethylation of $\mathrm{VHL}$, protein expression is retained. Magnification 200x.

well-characterized MEN1-related PanNETs and studied DNA methylation of a large number of tumor suppressor genes. We show that hypermethylation of $\mathrm{CpG}$ sites in promoter regions of tumor suppressor genes is a common event in both sporadic and MEN1-related PanNETs. This suggests that similar DNA methylation mechanisms play a role in both MEN1-dependent and -independent tumors (8). We found differences in frequency and in levels of CASP8 methylation between MEN1-related and sporadic tumors. In this light, the finding that methylation percentages of CASP8 are higher in MEN1-related PanNETs and in sporadic PanNETs negative for menin staining compared to sporadic PanNETs with retained menin expression, is of specific interest. CASP8 encodes the caspase- 8 protein with a central role in activation of apoptosis (24). Inactivation of CASP8 by DNA promoter methylation is a well-described event in development and progression of various tumor types such as neuroblastoma, glioblastoma multiforme and pheochromocytoma (25, $26,27)$. Recently, Stefanoli and coworkers observed a high frequency of CASP8 DNA promoter hypermethylation in sporadic PanNETs, which is in line with our results (31). It has been shown before in murine embryonic embryoblasts that menin suppresses tumor formation by inducing apoptosis via caspase 8 expression (28). Menin might prevent the CASP8 promoter from being methylated, possibly by inducing histone $\mathrm{H} 3$, lysine 4 (H3K4) methylation, which is known to counteract DNA methyltransferase activity (29). The high frequency of DNA promoter hypermethylation of the CASP8 promoter in MEN1-related PanNETs supports this hypothesis.

In MEN1 patients, cumulative DNA promoter methylation was found to be higher in large PanNETs and in PanNETs concurrent with liver metastases. These results 
imply that there is a role of DNA promoter methylation in tumor progression. DNA promoter methylation could, therefore, also be a therapeutic target in MEN1 patients with advanced PanNETs.

The tumor suppressor gene RASSF1 is considered to be the most frequently altered gene by DNA promoter methylation in sporadic PanNETs to date (4). This gene is involved in induction of cell cycle arrest and is inactivated by methylation in various cancers (30). DNA promoter hypermethylation of this gene has been reported before in $63-83 \%$ of sporadic (predominantly non-functioning) PanNETs $(31,32,33,34)$, which is comparable to the frequency of hypermethylation in the sporadic PanNETs included in our study. Interestingly, in MEN1, nearly all PanNETs are hypermethylated at the RASSF1 promoter (99\% and 97\% for RASSF1_2 and RASSF1_1 respectively) indicating that this is a frequent molecular event in MEN1-associated PanNET development. RASSF1 median methylation percentages were higher in insulinomas compared to non-functioning PanNETs in MEN1. Indeed, it has been shown before that loss of menin promotes $\beta$-cell proliferation by influencing the RAS signaling pathway (including RASSF1), but the exact mechanism remains unclear (35).

As in sporadic PanNETs, DNA promoter hypermethylation of MGMT was frequent in MEN1 tumors, especially in non-functioning PanNETs. Our results are in line with a previously reported hypermethylation frequency of MGMT in sporadic non-functioning PanNETs of approximately 40\% (32). The MGMT gene product 06-methylguanine DNA-methyltransferase provides resistance to treatment with alkylating agents such as temozolomide (36). MGMT promoter methylation could increase sensitivity to temozolomide and serve as a predictive biomarker of response to chemotherapy in MEN1 patients with advanced disease (37).

In one MEN1-related PanNET (WHO grade 2), a high methylation percentage of the VHL promoter was found together with loss of VHL protein expression. It has been reported that somatic VHL mutations and LOH of chromosomal locus $3 p$ (with the site of $V H L$ ) may be involved in PanNET development and/or progression in MEN1 $(38,39)$. DNA promoter hypermethylation of $V H L$ has previously been described in $6 \%$ of sporadic PanNETs (40). To our knowledge, this is the first report of VHL promoter hypermethylation in a MEN1 PanNET.

The importance of epigenetics in progression of PanNETs was demonstrated before. Mutations in the chromatin remodelers DAXX (death domain-associated protein) and ATRX (alpha thalassemia/mental retardation syndrome X-linked) occur in $43 \%$ of the sporadic cases (8). Mutations in these genes correlate well with loss of nuclear expression by IHC and this predicts metastatic disease and poor survival in patients with PanNETs (41). Also in MEN1 PanNETs, loss of nuclear expression of DAXX or ATRX is a late event (42). Analysis of our data according to DAXX/ATRX expression status in MEN1-related PanNETs did not reveal effects on the cumulative methylation nor on the methylation status of the CASP8, MGMT and VHL genes (data not shown). In summary, DNA promoter hypermethylation of tumor suppressor genes is a common event in MEN1-related and sporadic PanNETs. Promoter methylation may contribute to PanNET development and progression in MEN1. Targeting DNA methylation could be of therapeutic value in MEN1 patients with PanNETs.

\section{Supplementary data}

This is linked to the online version of the paper at https://doi.org/10.1530/ EJE-18-0195.

Declaration of interest

The authors declare that there is no conflict of interest that could be perceived as prejudicing the impartiality of the research reported.

\section{Funding}

Gerlof D Valk and Menno R Vriens are the receivers of an unrestricted grant from Ipsen.

\section{Acknowledgement}

The authors thank Prof. Dr P J van Diest for kindly providing the anti-VHL antibody.

\section{References}

1 Esteller M. Epigenetics in cancer. New England Journal of Medicine 2008358 1148-1159. (https://doi.org/10.1056/NEJMra072067)

2 Esteller M. Relevance of DNA methylation in the management of cancer. Lancet Oncology 20034 351-358. (https://doi.org/10.1016/ S1470-2045(03)01115-X)

3 Jones PA, Issa JP \& Baylin S. Targeting the cancer epigenome for therapy. Nature Reviews Genetics 201617 630-641. (https://doi. org/10.1038/nrg.2016.93)

4 Karpathakis A, Dibra H \& Thirlwell C. Neuroendocrine tumours: cracking the epigenetic code. Endocrine-Related Cancer 201320 R65-R82. (https://doi.org/10.1530/ERC-12-0338)

5 Halfdanarson TR, Rubin J, Farnell MB, Grant CS \& Petersen GM. Pancreatic endocrine neoplasms: epidemiology and prognosis of pancreatic endocrine tumors. Endocrine-Related Cancer 200815 409-427. (https://doi.org/10.1677/ERC-07-0221)

6 Fraenkel M, Kim M, Faggiano A, de Herder WW, Valk GD \& Knowledge NETwork. Incidence of gastroenteropancreatic neuroendocrine tumours: a systematic review of the literature. Endocrine-Related Cancer 201421 R153-R163. (https://doi. org/10.1530/ERC-13-0125) 
7 Capurso G, Festa S, Valente R, Piciucchi M, Panzuto F, Jensen RT \& Delle Fave G. Molecular pathology and genetics of pancreatic endocrine tumours. Journal of Molecular Endocrinology 201249 R37-R50. (https://doi.org/10.1530/JME-12-0069)

8 Jiao Y, Shi C, Edil BH, de Wilde RF, Klimstra DS, Maitra A, Schulick RD, Tang LH, Wolfgang CL, Choti MA et al. DAXX/ATRX, MEN1, and mTOR pathway genes are frequently altered in pancreatic neuroendocrine tumors. Science 2011331 1199-1203. (https://doi. org/10.1126/science.1200609)

9 Scarpa A, Chang DK, Nones K, Corbo V, Patch AM, Bailey P, Lawlor RT, Johns AL, Miller DK, Mafficini A et al. Whole-genome landscape of pancreatic neuroendocrine tumours. Nature 2017543 65-71. (https://doi.org/10.1038/nature21063)

10 Chandrasekharappa SC, Guru SC, Manickam P, Olufemi SE, Collins FS, Emmert-Buck MR, Debelenko LV, Zhuang Z, Lubensky IA, Liotta LA et al. Positional cloning of the gene for multiple endocrine neoplasia-type 1. Science 1997276 404-407. (https://doi. org/10.1126/science.276.5311.404)

11 Knudson AG Jr. Mutation and cancer: statistical study of retinoblastoma. PNAS 197168 820-823. (https://doi.org/10.1073/ pnas.68.4.820)

12 Pieterman CR, Conemans EB, Dreijerink KM, de Laat JM, Timmers HT, Vriens MR \& Valk GD. Thoracic and duodenopancreatic neuroendocrine tumors in multiple endocrine neoplasia type 1 : natural history and function of menin in tumorigenesis. EndocrineRelated Cancer 201421 R121-R142. (https://doi.org/10.1530/ERC-130482)

13 Hackeng WM, Brosens LA, Poruk KE, Noë M, Hosoda W, Poling JS, Rizzo A, Campbell-Thompson M, Atkinson MA, Konukiewitz B, Klöppel $\mathrm{G}$ et al. Aberrant menin expression is an early event in pancreatic neuroendocrine tumorigenesis. Human Pathology 201656 93-100. (https://doi.org/10.1016/j.humpath.2016.06.006)

14 Conemans EB, Nell S, Pieterman CRC, de Herder WW, Dekkers OM, Hermus AR, van der Horst-Schrivers AN, Bisschop PH, Havekes B, Drent ML et al. Prognostic factors for survival of MEN1 patients with duodenopancreatic tumors metastatic to the liver: results from the DMSG. Endocrine Practice 201723 641-648. (https://doi.org/10.4158/ EP161639.OR)

15 Conemans EB, Raicu-Ionita GM, Pieterman CRC, Dreijerink KMA, Dekkers OM, Hermus AR, de Herder WW, Drent ML, van der Horst-Schrivers ANA, Havekes B et al. Expression of p27(Kip1) and p18(Ink4c) in human multiple endocrine neoplasia type 1-related pancreatic neuroendocrine tumors. Journal of Endocrinological Investigation 201741 655-661. (https://doi.org/10.1007/s40618-0170783-y)

16 Casparie M, Tiebosch AT, Burger G, Blauwgeers H, van de Pol A, van Krieken JH \& Meijer GA. Pathology databanking and biobanking in The Netherlands, a central role for PALGA, the nationwide histopathology and cytopathology data network and archive. Cellular Oncology 200729 19-24.

17 Bosman FT, Carneiro F, Hruban RH \& Theisse ND. WHO Classification of Tumours of the Digestive System. Lyon: International Agency for Research on Cancer (IARC), 2010.

18 Conemans EB, Brosens LAA, Raicu-Ionita GM, Pieterman CRC, de Herder WW, Dekkers OM, Hermus AR, van der Horst-Schrivers AN, Bisschop PH, Havekes B et al. Prognostic value of WHO grade in pancreatic neuro-endocrine tumors in Multiple Endocrine Neoplasia type 1: results from the DutchMEN1 Study Group. Pancreatology 2017 17 766-772. (https://doi.org/10.1016/j.pan.2017.07.196)

19 Nygren AO, Ameziane N, Duarte HM, Vijzelaar RN, Waisfisz Q, Hess CJ, Schouten JP \& Errami A. Methylation-specific MLPA (MS-MLPA): simultaneous detection of CpG methylation and copy number changes of up to 40 sequences. Nucleic Acids Research 2005 33 e128. (https://doi.org/10.1093/nar/gni127)

20 Suijkerbuijk KP, Fackler MJ, Sukumar S, van Gils CH, van Laar T, van der Wall E, Vooijs M \& van Diest PJ. Methylation is less abundant in BRCA1-associated compared with sporadic breast cancer. Annals of Oncology 200819 1870-1874. (https://doi.org/10.1093/annonc/ mdn409)

21 Moelans CB, Verschuur-Maes AH \& van Diest PJ. Frequent promoter hypermethylation of BRCA2, CDH13, MSH6, PAX5, PAX6 and WT1 in ductal carcinoma in situ and invasive breast cancer. Journal of Pathology 2011225 222-231. (https://doi. org/10.1002/path.2930)

22 Bol GM, Suijkerbuijk KP, Bart J, Vooijs M, van der Wall E \& van Diest PJ. Methylation profiles of hereditary and sporadic ovarian cancer. Histopathology 201057 363-370. (https://doi.org/10.1111/ j.1365-2559.2010.03642.x)

23 Gylling A, Abdel-Rahman WM, Juhola M, Nuorva K, Hautala E, Järvinen HJ, Mecklin JP, Aarnio M \& Peltomäki P. Is gastric cancer part of the tumour spectrum of hereditary non-polyposis colorectal cancer? A molecular genetic study. Gut 200756 926-933. (https:// doi.org/10.1136/gut.2006.114876)

24 Li J \& J Yuan. Caspases in apoptosis and beyond. Oncogene 200827 6194-6206. (https://doi.org/10.1038/onc.2008.297)

25 Decock A, Ongenaert M, Vandesompele J \& Speleman F. Neuroblastoma epigenetics: from candidate gene approaches to genome-wide screenings. Epigenetics 20116 962-970. (https://doi. org/10.4161/epi.6.8.16516)

26 Martinez R, Setien F, Voelter C, Casado S, Quesada MP, Schackert G \& Esteller M. CpG island promoter hypermethylation of the pro-apoptotic gene caspase-8 is a common hallmark of relapsed glioblastoma multiforme. Carcinogenesis 200728 1264-1268. (https://doi.org/10.1093/carcin/bgm014)

27 Margetts CD, Astuti D, Gentle DC, Cooper WN, Cascon A, Catchpoole D, Robledo M, Neumann HP, Latif F \& Maher ER. Epigenetic analysis of HIC1, CASP8, FLIP, TSP1, DCR1, DCR2, DR4, DR5, KvDMR1, H19 and preferential 11p15.5 maternal-allele loss in von Hippel-Lindau and sporadic phaeochromocytomas. Endocrine-Related Cancer 200512 161-172. (https://doi.org/10.1677/ erc.1.00865)

28 Schnepp RW, Mao H, Sykes SM, Zong WX, Silva A, La P \& Hua X. Menin induces apoptosis in murine embryonic fibroblasts. Journal of Biological Chemistry 2004279 10685-10691. (https://doi. org/10.1074/jbc.M308073200)

29 Yang Y \& X Hua. In search of tumor suppressing functions of menin. Molecular and Cellular Endocrinology 2007 265-266 34-41. (https:// doi.org/10.1016/j.mce.2006.12.032)

30 Agathanggelou A, Cooper WN \& Latif F. Role of the Ras-association domain family 1 tumor suppressor gene in human cancers. Cancer Research 200565 3497-3508. (https://doi.org/10.1158/0008-5472. CAN-04-4088)

31 Dammann R, Schagdarsurengin U, Liu L, Otto N, Gimm O, Dralle H, Boehm BO, Pfeifer GP \& Hoang-Vu C. Frequent RASSF1A promoter hypermethylation and K-ras mutations in pancreatic carcinoma. Oncogene 200322 3806-3812. (https://doi.org/10.1038/ sj.onc.1206582)

32 House MG, Herman JG, Guo MZ, Hooker CM, Schulick RD, Lillemoe KD, Cameron JL, Hruban RH, Maitra A \& Yeo CJ. Aberrant hypermethylation of tumor suppressor genes in pancreatic endocrine neoplasms. Annals of Surgery 2003238 423-431; discussion 431-432. (https://doi.org/10.1097/01.sla.0000086659.49569.9e)

33 Liu L, Broaddus RR, Yao JC, Xie S, White JA, Wu TT, Hamilton SR $\&$ Rashid A. Epigenetic alterations in neuroendocrine tumors: methylation of RAS-association domain family 1, isoform A and p16 genes are associated with metastasis. Modern Pathology 200518 1632-1640. (https://doi.org/10.1038/modpathol.3800490)

34 Malpeli G, Amato E, Dandrea M, Fumagalli C, Debattisti V, Boninsegna L, Pelosi G, Falconi M \& Scarpa A. Methylationassociated down-regulation of RASSF1A and up-regulation of RASSF1C in pancreatic endocrine tumors. BMC Cancer 201111351. (https://doi.org/10.1186/1471-2407-11-351) 
35 Chamberlain CE, Scheel DW, McGlynn K, Kim H, Miyatsuka T, Wang J, Nguyen V, Zhao S, Mavropoulos A, Abraham AG et al. Menin determines K-RAS proliferative outputs in endocrine cells. Journal of Clinical Investigation 2014124 4093-4101. (https://doi.org/10.1172/ JCI69004)

36 Gerson SL. MGMT: its role in cancer aetiology and cancer therapeutics. Nature Reviews Cancer 20044 296-307. (https://doi. org/10.1038/nrc1319)

37 Cros J, Hentic O, Rebours V, Zappa M, Gille N, Theou-Anton N, Vernerey D, Maire F, Lévy P, Bedossa P et al. MGMT expression predicts response to temozolomide in pancreatic neuroendocrine tumors. Endocrine-Related Cancer 201623 625-633. (https://doi. org/10.1530/ERC-16-0117)

38 Hessman O, Lindberg D, Einarsson A, Lillhager P, Carling T, Grimelius L, Eriksson B, Akerström G, Westin G \& Skogseid B. Genetic alterations on 3p, 11q13, and 18q in nonfamilial and MEN 1-associated pancreatic endocrine tumors. Genes, Chromosomes and Cancer 199926 258-264. (https://doi.org/10.1002/(SICI)10982264(199911)26:3<258::AID-GCC11>3.0.CO;2-2)

39 Shell J, Patel D, Powers A, Quezado M, Killian K, Meltzer P, Zhu J, Gaitanidis A, Karzai F, Neychev V et al. Somatic VHL mutation in a patient with MEN1-associated metastatic pancreatic neuroendocrine tumor responding to sunitinib treatment: a case report. Journal of the Endocrine Society 20171 1124-1134. (https://doi.org/10.1210/js.201700156)

40 Schmitt AM, Schmid S, Rudolph T, Anlauf M, Prinz C, Klöppel G, Moch H, Heitz PU, Komminoth P \& Perren A. VHL

inactivation is an important pathway for the development of malignant sporadic pancreatic endocrine tumors. EndocrineRelated Cancer 200916 1219-1227. (https://doi.org/10.1677/ ERC-08-0297)

41 Singhi AD, Liu TC, Roncaioli JL, Cao D, Zeh HJ, Zureikat AH, Tsung A, Marsh JW, Lee KK, Hogg ME et al. Alternative lengthening of telomeres and loss of DAXX/ATRX expression predicts metastatic disease and poor survival in patients with pancreatic neuroendocrine tumors. Clinical Cancer Research 201723 600-609. (https://doi. org/10.1158/1078-0432.CCR-16-1113)

42 de Wilde RF, Heaphy CM, Maitra A, Meeker AK, Edil BH, Wolfgang CL, Ellison TA, Schulick RD, Molenaar IQ, Valk GD et al. Loss of ATRX or DAXX expression and concomitant acquisition of the alternative lengthening of telomeres phenotype are late events in a small subset of MEN-1 syndrome pancreatic neuroendocrine tumors. Modern Pathology 201225 1033-1039. (https://doi. org/10.1038/modpathol.2012.53)

Received 7 March 2018

Revised version received 27 May 2018

Accepted 14 June 2018 